automatic methods will shortly be brought into use. A small-scale rotational viscometer was also described; it has been found that the shear in this instrument destroys the rheological properties most nearly related to the changes in hormone condition of the animals.

The presidential address was followed by a paper by L. Grunberg and Dr. A. H. Nissan on "Viscosity, Constitution and Structure", with A. G. Ward in the chair. Mr. Grunberg outlined the history of the formula $\eta=A \exp (B / T)$ and its many variants. After considering the classification of liquids into "normal or dispersion liquids", "polar associated liquids", "ionic liquids" and "metallic liquids", the main part of the paper was concerned with the "normal liquids". In comparing two liquids, the need for choosing suitable conditions in each case was emphasized, and the choice of temperatures at which the vapour pressures are equal was justified on the basis of theoretical arguments. A simpler method involves the comparison of viscosities at equal $T / T_{B}$ where $T$ is the temperature for the viscosity measurement and $T_{B}$ is the boiling point under atmospheric pressure. The results of the application of this method to hydrocarbons and their halogen derivatives were given together with conclusions derived from the study of $E_{\text {visc. }} / M(=R B / M)$, where $M$ is the molecular weight. The relation of the heat of mixing to viscosity data for regular solutions was also given. A short contribution was made to the discussion by Dr. A. Nisbet, outlining the theory of viscosity developed by Born and Green.

The opening session on September 29 consisted of a paper by W. G. Harland and W. A. Richardsion on "Intrinsic Viscosity", J. G. Oldroyd being in the chair. Mr. Richardson showed how important an exact statement of the procedure followed can be in determining the intrinsic viscosity of solutions. He reviewed the many equations which have been developed to express the concentration dependence of the viscosity of polymer solutions, and also the terminology which has been suggested by different authors. Mr. Richardson expressed the firm opinion that it is better to ensure that the terms used-specific viscosity, intrinsic viscosity, reduced viscosity, etc.should be those with the greatest chance of widespread adoption, rather than that an attempt should be made to impose a logical and rational new set of terms. Discussion following the paper showed general agreement with $\mathrm{Mr}$. Richardson's views.

The paper by Dr. F. R. Eirich (Brooklyn) on "Flow Birefringence: Some Results on Concentrated Polymer Solutions" was, in Dr. Eirich's absence, read by Dr. E. W. J. Mardles. A. H. Nissan was in the chair. The relation of the intrinsic viscosity, sedimentation constant, translational diffusion constant and rotatory diffusion constant to molecular size, shape and molecular weight were first discussed. The need for two measurements of this type to enable molecular constants to be calculated was emphasized. Particular attention was given to the combination of the intrinsic viscosity with the rotatory diffusion constant, the latter being determined from the extinction angle, and to the relation of the results to molecular models for chain molecules.

In the afternoon a visit was paid to the National Institute for Research in Dairying, Shinfield, Reading. Dr. Scott Blair and his collaborators showed exhibits illustrating work on the rheology of cheese and butter, including the use of factorial analysis, and also the apparatus used for cervical secretions. A film was shown of the scientific study of cheese testing, and a general tour of the Institute was arranged.

The evening session was devoted to papers by Dr. L. R. G. Treloar on "The Structure and Properties of Rubber", and by H. H. Macey on "The Flow of Clay Systems". Dr. V. W. G. Harrison was in the chair. Dr. Treloar reviewed the theory of rubber-like elasticity and the crystallization of rubber, and illustrated his paper by convincing demonstrations of the various effects. Mr. Macey developed a quantitative theory of the plasticity of clay-water systems based on the forces of interaction between the clay particles. The interaction can be represented by repulsive forces which are compensated at the boundary by surface tension. The theory is able to give both a qualitative and quantitative interpretation of much of the experimental results for plastic clay. Considerable discussion followed Mr. Macey's paper concerning the nature of the water film between the clay particles, and whether any structure is imparted to the water by the forces from the clay particle surface over distances of more than a few molecular diameters.

The morning session of September 30 was devoted to the rheology of metals, with Prof. M. Reiner (Haifa Technical College) in the chair. The first paper, "The Role of Structural Discontinuities in Crystal Plasticity", was given by K. E. Puttick and M. W. Thring. Emphasis was placed on the importance of the rate of strain in measurements of yield of metal. The theories explaining yield in terms of dislocations were described and related to the experimental results. P. Feltham in his paper, "Trends in the Rheology of Metals at High Temperatures", stressed the dangers of approaching so complex a field from a narrow or mechanistic point of view. This was shown to lead to a divorce between 'pure' physical studies, suited to the academic worker, and 'applied' metallurgical studies which are left to the works laboratory. These considerations were illustrated by the inelastic beheviour of metels at high temperatures.

ALAN G. WARD

\section{THE AGRICULTURAL AND HORTICULTURAL RESEARCH STATION, LONG ASHTON \\ ANNUAL REPORT FOR 1948}

THE University of Bristol Agricultural and Horticultural Research Station, at Long Ashton, maintains its tradition of balanced practical research into problems of fruit growing and fruit products. In its annual report for 1948*, Dr. L. C. Luckwill reports that alpha-naphthalene acetic acid (5 p.p.m.), 2:4 dichlorophenoxy-acetic acid (1 p.p.m.) and indolyl-acetic acid (5 p.p.m.) all reduced fruit-set without causing damage to the foliage. These substances were applied as sprays shortly after the time of full blossom, and are designed to control superabundant fruiting, with subsequent abscission and loss of too much fruit. Dr. Luckwill has also studied the ecology of orchard cover crops, finding that rye-grass and clover mixtures tend to be replaced by creeping bent. The last-mentioned grass, however, is itself good for the purpose. C. Bould, J. A. H. Tol-

* University of Bristol. Annual Report of the Agricultural and Horticultural Research Station (the National Fruit and Cider In-
atitute) University, 1949.) 
hurst and R. M. Jarrett have investigated the effect of cover crops on fruit-tree nutrition, finding they had little effect on yield and girth increase, but lowered the nitrogen content of foliage, as compared with clean cultivation. C. Bould and J. Tolhurst bring further evidence that magnesium deficiency of fruit trees can be cured effectively by three or four foliage sprays of 2 per cent magnesium sulphate.

Prof. T. Wallace, director of Long Ashton Research Station, leads a group of workers on problems of plant nutrition, the present papers dealing mainly with the effects of farmyard manure on potatoes (with E. Catlow). E. J. Hewitt has an interesting paper on the resolution of factors in soil acidity, discussing the relative effects of aluminium and manganese toxicities. The same worker reports on iron deficiency and (with E. W. Jones) on molybdenum deficiency.

Dithiocarbamates, organic mercurials, substituted quinols and glyoxalidine derivatives have been suggested as alternatives to lime sulphur spray for the control of plant diseases. These are described in a short paper by R. W. Marsh; glyoxalidine seemed to give the most promising results. The proper healing of wounds is an important factor in plant pathology. S. H. Crowdy has studied the effect of organic chemicals on the process, and makes the suggestion that the inclusion of plant growth substance in wound dressings may have advantages. Some promising results on the control of brown rot of fruits by spraying with phenyl mercury chloride are reported by R. J. W. Byrde. The insecticide DDT has attained such popularity that it is natural to investigate the toxic properties of its analogues. This is being done by S. H. Bennett, H. Martin, A. Stringer and D. Woodcock, who issue a progress report.

A former director of the Station, Prof. B. T. P. Barker, contributes a paper on 'cider sickness', finding at least three different bacteria which can cause it. S. W. Challinor and L. F. Burroughs contribute two papers dealing with the role of nitrogen in fermentation, as part of a fundamental study of the chemistry of cider. As another part of the inquiry into cider-making processes, Margaret E. Kieser, A. Pollard and Audrey M. Stone report on the pectose activity of some apple varieties. The browning of processed pears can be avoided by quick processing, to attain temperatures which inactivate the enzymes (Dilys James and Alice Crang).

The research at Long Ashton is thus a welcome blend of fundamental and applied studies, and the report itself is informative. It is now edited by G. T. Spinks, who is to be congratulated on the maintenance of its high standard of production.

\section{HIGH-TEMPERATURE ADIABATIC CALORIMETRIC MEASUREMENTS OF THE TRANSITION METALS}

$\mathrm{T}$

HE advantage of adiabatic calorimetry is that it allows specific heats to be measured directly over small temperature intervals and thus to obtain details of the variation of specific heat with temperature. Until recently, however, because of the difficulties of adequate thermal insulation at high temperatures, accurate work with adiabatic calorimeters was not possible at temperatures above $500^{\circ} \mathrm{C}$. Further, the atomic heats of metals in the transition group, chromium to nickel, are of considerable theoretical interest; but reliable data at high temperatures exist for iron and njckel only. Two papers which appeared in the January issue of the Canadian Journal of Research ${ }^{1}$ are therefore of considerable interest. In the first, a description is given by L. D. Armstrong of the construction of a new high-temperature adiabatic calorimeter which, by making use of special techniques developed previously for the measurement of thermal conductivities at high temperatures ${ }^{2}$, can be used for making reliable determinations of specific heats up to $800^{\circ} \mathrm{C}$.

The specimen, either a machined cone of solid metal or in the form of a powder or loose pieces packed firmly together, fits into a copper container, and the specimen and container are electrically heated. The surrounding copper radiation jacket, which is maintained at a temperature as close as possible to that of the container, is supported inside an electrical furnace which can be evacuated or filled with an inert gas. Temperatures are measured by thermocouples. The heat capacity of the empty calorimeter is determined by two series of measure. ments : one with the calorimeter empty; and the other with the calorimeter filled with the standard material, aluminium oxide in the form of synthetic sapphire, the specific heat of which is known accur. ately from the work of D. C. Ginnings and R. J. Corruccini $^{3}$. It is claimed that specific heat values derived from a smoothed specific heat/temperature curve obtained from measurements made with the adiabatic calorimeter are correct to within I per cent.

In the second paper, measurements of the specific heats of chromium, manganese and cobalt made with the adiabatic calorimeter are described by $L$. $D$. Armstrong and H. Grayson-Smith. The chromium used was in the form of electrolytic flakes and was 99.9 per cent pure. The atomic heat of chromium is regular from 0 to $800^{\circ} \mathrm{C}$., increasing steadily above $100^{\circ} \mathrm{C}$. to values considerably in excess of the classical value $3 R$. For manganese, in the form of electrolytic nodules and of 99.99 per cent purity but slightly discoloured by surface oxidation, the measurements show that the atomic heat is quite regular from 0 to $700^{\circ} \mathrm{C}$. with values considerably greater than $3 R$. At $717^{\circ} \mathrm{C}$. the transition from the $\alpha$ - to the $\beta$-phase takes place sharply with a latent heat of $450 \mathrm{cal} . / \mathrm{mol}$. Supercooling occurs on cooling from the $\beta$ - to the $\alpha$-phase. Except for the interval 447$478^{\circ} \mathrm{C}$., where cobalt changes its structure on heating from hexagonal close-packed to face-centred cubic, the atomic heat increases regularly. The heat of transition was estimated to be $60 \mathrm{cal} . / \mathrm{mol}$. approximately.

The experimental values are used for a theoretical discussion of the atomic heats of the transition metals, all of which are considerably greater than $3 R$ at high temperatures. The excess specific heats of the ferromagnetic substances cobalt and nickel can be accounted for by the ferromagnetism and the conduction electrons. For chromium and manganese, after allowance is made for the conduction electrons, there is still a large residual excess specific heat indicating some unknown source of internal energy, attributed tentatively to antiferromagnetism. It is suggested that the two metals may have antiferromagnetic Curie points at temperatures above $800^{\circ} \mathrm{C}$., but there is little evidence at present to support such a proposal.

${ }^{1}$ Canadian J. Res., 28A, 44 and 51 (1950).

'Canadian J. Res., $25 \mathrm{~A}, 357$ (1947).

J J. Reg. Nat. Bur. Standards, 38, 583 (1947). 